\title{
ENSINO DE GEOGRAFIA COM O USO DE FILMES NO BRASIL
}

Tiago de Almeida Moreira ${ }^{1}$

Resumo: O artigo faz uma revisão sobre ensino de Geografia com uso de filmes no Brasil, apresentando onze trabalhos sobre o tema. É apresentado também um inventário de filmes sobre temas relativos à Geografia. A partir disto são feitas discussões que mostram que há algumas dificuldades para o uso de filmes nas escolas, mas que também há grandes possibilidades. Este é um tema ainda pouco estudado no Brasil, e o trabalho traz uma contribuição inicial à questão.

Palavras-Chave: Didática; Ensino de Geografia; Recursos Audiovisuais.

\section{GEOGRAPHY TEACHING USING MOVIES ON BRAZYL}

Abstract: The paper makes a review about Geography teaching using movies on Brazyl, presenting eleven works about the theme. Is also presented an inventory of movies relative by the Geography. By this are make discussions that shows there are some difficulties to use movies on the schools but are big possibilities too. This is a theme who have a few of researches on Brazyl and this work brings an initial contribution to the question.

Key-Words: Didactics; Geography Teaching; Audio Visual Resources.

\section{INTRODUÇÃO}

O artigo traz uma contribuição inicial do autor, a uma área de discussão ainda recente no Brasil, o uso de filmes no Ensino de Geografia. A revisão bibliográfica sobre o tema, que é apresentada no item a seguir, introduz o trabalho, e evidencia que ainda há poucos trabalhos sobre o assunto. Em seguida são feitas algumas considerações sobre as dificuldades de se utilizar filmes nas escolas. O item seguinte apresenta algumas possibilidades de uso de filmes em sala de aula. O tópico subsequente apresenta uma lista com cento e vinte e cinco filmes, subdivididos entre vinte e cinco temas/conteúdos da Geografia. Ao final, são feitas considerações gerais e apresentadas as referências bibliográficas.

A escassa bibliografia sobre o assunto no Brasil, apenas onze trabalhos anteriores citados neste artigo, aliada à relevância do tema no tempo atual, cada vez mais mediado pelas mídias, motivaram o interesse do autor em desenvolver este trabalho. Esta revisão

\footnotetext{
${ }^{1}$ Licenciado em Geografia pela Universidade Estadual de Feira de Santana-BA e Mestrando em Geografia pela Universidade de Brasília-UnB - E-mail: tiagoalmeidamoreira@gmail.com DOI: 10.7154/RDG.2012.0023.0003
} 
bibliográfica, discussão de dificuldades e possibilidades de uso didático de filmes, bem como o inventário de filmes relativos a temas geográficos, visa contribuir para o Ensino de Geografia e áreas afins, tais como a História, Sociologia, Antropologia, Comunicação etc. As discussões ora apresentadas deverão ser aprofundadas em trabalhos posteriores.

\section{Os Caminhos da Pesquisa}

A metodologia de pesquisa deste trabalho baseia-se basicamente em pesquisa bibliográfica sobre o Ensino de Geografia no Brasil com o uso de filmes, bem como na análise crítica de toda a bibliografia obtida, para subsidiar a discussão sobre as dificuldades e possibilidades do uso de filmes no Ensino de Geografia. Além disso, foi feita a pesquisa - compilação fílmica de obras que tratam de temas geográficos, contendo um breve comentário sobre cada um dos cento e vinte e cinco filmes listados. Este é um trabalho introdutório sobre o assunto, um inventário de outros trabalhos sobre o tema, bem como de filmes que podem ser usados no Ensino de Geografia. Esta primeira contribuição do autor é o passo inicial de uma caminhada investigativa a ser aprofundada futuramente.

\section{Geodidática Fílmica no Brasil}

... dentre todas as formas artísticas, ele [o cinema] tem talvez a capacidade mais robusta de tratar de maneira instrutiva de temas entrelaçados do espaço e do tempo.

David Harvey A primeira citação apresentada acima, de Harvey (1992), introduz a relevância da discussão ora apresentada. Há quase duas décadas o autor de Condição Pós-Moderna já chamava atenção para a potencialidade instrutiva do cinema, e de seu papel nas representações de processos e fenômenos sócioespaciais. O autor dedicou um capítulo inteiro de seu referido livro para discutir representações sobre a Pós-Modernidade, analisando dois filmes: Blade Runner - O Caçador de Andróides, dirigido por Ridley Scott - 1982, e Asas do Desejo, de Wim Wenders - 1987. Este trabalho chamou atenção dos cientistas sociais, e em especial dos geógrafos, para o papel dos filmes como objeto de análise geográfica e como recurso didático a ser utilizado no ensino de Geografia. 
A cooperativa barcelonense de artes e educação Drác Magic, é utilizada por Pellicer (1995) como estudo de caso, e exemplo de uma iniciativa bem sucedida de utilização do cinema como recurso didático. Para a autora, mesmo com o êxito, os desafios são grandes: "La educación audiovisual y cinematográfica, afecta a todos los ciudadanos y, por tanto, creemos que los trabajos aislados de divulgación del cine em las escuelas, aún siendo muy válidos, no son suficientes como garantía para la consecución de esta importante meta". Presume-se a partir da idéia apresentada, que se mesmo em uma grande cidade de um país desenvolvido, como no caso Barcelona - Espanha, os desafios são constantes, no Brasil este é um processo ainda em fase de fortalecimento e estruturação.

A experiência de dois professores do ensino médio da cidade de Sevilha, também na Espanha, com a utilização de filmes, dentre outros recursos didáticos, no Ensino de Geografia e História mostrou-se bastante positiva. Para Valero e Vera (1998): “... el aprendizage audiovisual es uma de las mejores formas de motivación para el alumnado y para fomentar el aprendizage". Estes e outros autores aqui citados ressaltam o caráter dinâmico e atrativo com os quais os alunos podem ser instigados, provocados e envolvidos em discussões sobre diferentes assuntos a partir da exibição e discussão de filmes em sala de aula.

Betanzo (2010) defende o uso do cinema na busca da construção de uma aprendizagem mais concreta, ativa e reflexiva, pois, de acordo com o autor: "La reflexividad e la interdisciplinariedad obtenida a través de esta valiosa herramienta visual puede llegar a produzir alumnos mas comprometidos com su que hacer acadêmico, así como, ampliar su horizonte formativo". O ponto de vista do autor ressalta a possibilidade de uma prática pedagógica reflexiva e interdisciplinar com o uso de filmes, vale destacar que, o uso de filmes nas escolas pode propiciar o trabalho em parceria de professores de diferentes áreas, como por exemplo Geografia, História e Sociologia, em conjunto cada um pode discutir conteúdos referentes à sua área através de um mesmo filme analisado, e discutir as interfaces entre esses conteúdos.

Em Portugal também aparecem estudos e trabalhos que destacam a importância didática dos filmes para o Ensino de Geografia, como exemplo Bértolo (2001) afirma que: “... minha conviç̧ão que o uso dos media cinemáticos, particularmente de formas documentárias, na representação do espaço poderá ter efeitos fecundos nos âmbitos da geografia e das restantes disciplinas que têm por objecto de estudo as dimensões espaciais...". O autor 
ressalta a potencialidade do uso do audiovisual, tanto para a documentação de processos e fenômenos sócioespaciais, quanto para a utilização em sala de aula, idéia incorporada também pelo autor deste artigo.

No Brasil, idéias sobre a utilização de filmes como recurso didático começam a surgir desde as décadas de 1920 e 30, como aponta Catelli (2010), através das influências das perspectivas pedagógicas da Escola Nova. De acordo com a autora, educadores brasileiros do período, influenciados por ações já em prática na França e nos EUA, reuniram esforços para elaborar uma proposta de um cinema educativo no Brasil. Entretanto, desde aquela época, estes pioneiros já esbarravam na burocracia estatal para a compra e manutenção dos equipamentos, bem como na precariedade das escolas para se implementar e manter tal tipo proposta. Infelizmente, nos dias atuais, estes ainda são dois obstáculos recorrentes.

Leandro (2001) defende a idéia de uma pedagogia da imagem, na qual imagem e mensagem não são dissociadas, pois que todo filme traz em si diversos discursos. A autora alerta que, muitos professores têm passado a adotar o uso de filmes em sala de aula, sem fazerem um trabalho adequado de análise crítica dos discursos apresentados, acabando por reforçar certos estereótipos e estimular certa supervalorização da imagem em detrimento da linguagem. Se imagem é discurso, é papel premente dos professores de Geografia mediarem e estimularem a formação de leitores críticos, para a leitura da miríade de imagens e mensagens que acessamos cotidianamente.

A produção de vídeos documentários pode ser uma ferramenta bastante útil ao Ensino de Geografia, como destaca Ramos Filho (2005), afirmando que, “... o cinema e o vídeo na escola devem ultrapassar a dinâmica do lazer. Porém sem negá-la. A escola deve ser ambiciosa e instrumentalizar o aluno para que ele se torne um espectador mais exigente e crítico". Neste sentido, o uso de filmes em sala de aula e a organização de cineclubes, podem despertar o interesse dos estudantes para vários temas e questões trabalhados pela Geografia, bem como estimular uma mudança de olhar sobre sua própria realidade.

Campos (2006) chama atenção para o uso de recursos audiovisuais em sala de aula por parte dos professores de Geografia. Além de tecer várias considerações sobre a questão, o autor indica uma grande lista de filmes, relacionando-os com temas clássicos da Geografia, como sugestão para o uso em sala. Apesar de destacar o potencial dos filmes como recurso didático ao ensino de Geografia, o autor adverte que todo filme tem sua intencionalidade e, “O cinema não é, portanto, um registrador da realidade (...) Além de subjetivo, não é uma 
construção isolada do sistema sócio-cultural do qual se origina". Os filmes trazem um discurso subjacente, relacionado com a bagagem intelectual do seu autor, suas intencionalidades, deste modo, deve ser lido criticamente.

A imagem como forma de representação do mundo sempre fez parte da Geografia, como salienta Pontuschka (2007), desde as aquarelas dos antigos viajantes, passando pelos mapas, cartas, fotos, maquetes, globos, imagens de satélite etc. A autora defende que a linguagem cinematográfica deve ser incorporada a este elenco de técnicas de registro e representação, seja no seu uso voltado para o Ensino de Geografia, seja na análise geográfica dos filmes, ou mesmo como forma de documentação de vários processos estudados pela Geografia. A autora enfatiza que, "Para nós, geógrafos e professores de Geografia, o filme tem importância porque pode servir de mediação para o desenvolvimento das noções de tempo e de espaço na abordagem dos problemas sociais, econômicos e políticos".

O trabalho de Rivero (2007) defende o papel instrumental do cinema como recurso didático, segundo o mesmo, “... o cinema na sala de aula pode se transformar em uma ferramenta prática, eficiente e prazerosa no processo de aprendizagem". O autor reforça ainda a atração que este recurso pode propiciar aos jovens estudantes, ao afirmar que: "Este recurso [o cinema] é muito rico, lúdico e prazeroso, tendo um potencial fantástico para o aprendizado de qualquer público, principalmente dos jovens". Vale ressaltar que, dentre os trabalhos aqui listados este é o mais aprofundado em sua investigação, uma monografia de final de curso, e suas reflexões finais destacam sobremaneira o papel do cinema no Ensino de Geografia.

A Formação Estética Visual é a proposta defendida por Duarte e Alegria (2008), idéia posta em prática em projetos de difusão de cinema em escolas públicas do Rio de Janeiro, através de uma parceria com o Ministério da Cultura da França. O projeto é interessante, e os autores buscam dar destaque especial à dimensão estética nos filmes, para com isso sensibilizar os estudantes para conteúdos específicos. Os autores priorizam a formação de cinéfilos e ou videófilos, ao defenderem a formação estética visual. Contudo, para além da formação de cinéfilos, é importante se pensar na formação de leitores críticos de discursos cinematográficos, através da pedagogia da imagem, como defende Leandro (2001), citado anteriormente.

O uso de filmes de ficção, documentários e desenhos animados no ensino de Geografia é discutido por Pereira e Silveira (2009). O trabalho discute sobre a necessidade de se 
estimular nos alunos a busca da construção de um senso crítico do que é visto por eles nos filmes, documentários e desenhos, na televisão e internet. Outro aspecto é a valorização do uso destes veículos de comunicação e informação como recurso didático no ensino de Geografia. Os autores constroem um esboço de proposta metodológica a ser adequada a cada realidade escolar, sugerindo atividades, formas de avaliação e uma pequena lista de filmes, servindo de base inicial aos professores que queiram utilizar filmes em seu trabalho docente.

Ramos Filho (2009) relata sua experiência prática na realização de dois documentários sobre comunidades campesinas no Sergipe. O professor-pesquisador envolveu na realização dos dois filmes, tanto as comunidades retratadas, como seus alunos de ensino médio e superior. Através de uma metodologia democrática e participativa, o autor informa que o processo de feitura dos documentários envolveu ativamente todos os sujeitos do projeto, o que gerou um ambiente dinâmico e criativo. O processo de trabalho como um todo, bem como o seu resultado final, parece ter propiciado um ambiente de ensino-aprendizagem bastante fecundo. Metodologia similar é relatada por Santos Filho e Nunes (2009), na realização de documentário sobre a Bacia do Rio Bengalas, em Nova Friburgo - RS.

O uso de filmes no ensino de representações sobre África é o tema trabalhado por Diniz e Araújo (2009), que apresentam um catálogo com filmes a serem utilizados sobre o conteúdo supracitado, bem como um relato de experiências de uso destes filmes em sala de aula. Os autores apontam que as atividades desenvolvidas serviram tanto para os alunos conhecerem muitos aspectos da África não mostrados nos livros didáticos, quanto para ajudar a desmistificar certos discursos estereotipados presentes em muitos filmes. Este último aspecto citado, na opinião do autor, é um dos mais importantes no uso de cinema no ensino de Geografia.

O uso de filmes no ensino é cada vez mais aceito, não só pelos professores de Geografia, mas também por professores de outras áreas afins, a saber: na História - Abud (2003), na Filosofia - Costa et al. (2008), na Sociologia - Dwyer (2010), na Antropologia - Zanini e Weber (2010), no Direito - Costa e Carvalho (2010), na Biologia - Cavalcante (2011), e em diversas outras áreas de conhecimento. Frente a isto, é importante que a Geografia busque diálogo e aproximação com essas outras áreas, no intuito da construção de um conhecimento abrangente e interdisciplinar. O uso de filmes nas escolas pode contribuir para a aproximação dos professores de Geografia com os de História, Literatura, Biologia, 
Sociologia etc., cada um com sua abordagem específica, analisando e debatendo sobre temas em comum a essas áreas.

A aproximação entre professores de áreas afins nem sempre é muito fácil de ser efetivada, como nem sempre é fácil a utilização de filmes na escola, de maneira geral, e na sala de aula, de forma mais específica. Algumas dificuldades infra-estruturais e burocráticas acabam obstaculizando este processo, a seguir serão feitas algumas considerações a respeito desta questão.

\section{As Dificuldades do Uso do Cinema nas Escolas}

Pellicer (1995) e Catelli (2010), citados no tópico anterior, já ressaltavam as dificuldades de se trabalhar com cinema nas escolas da rede pública, na Espanha e no Brasil, respectivamente. Vale aqui compartilhar desta inquietação apresentada pelos autores, e discorrer de maneira mais detalhada sobre as dificuldades estruturais e burocráticas de se utilizar filmes nas escolas brasileiras. Os obstáculos a serem citados a seguir se fazem presentes na maioria das escolas brasileiras da rede pública, com maior ou menor incidência, a depender das diferenças socioeconômicas regionais no nosso país. A identificação desses obstáculos pode servir de passo inicial para que professores e gestores escolares busquem se organizar, e suprir as lacunas existentes em seus respectivos estabelecimentos de ensino.

As dificuldades estruturais para o uso do cinema nas escolas são várias: falta de auditórios bem aparelhados para a exibição de filmes; falta de aparelhos de tv, de DVD, de projeção e de som, ou quantidade insuficiente destes frente ao número de professores que precisem utilizá-los; falta de manutenção das instalações e aparelhos; falta de acervo de filmes em dvd; falta de local adequado para a organização e manutenção de acervo; restrição na disponibilidade de funcionários para a gestão dos acervos e das salas de projeção; falta da devida segurança nas instalações das escolas, o que pode levar a arrombamentos e furto dos aparelhos etc. Estes são os principais problemas estruturais que dificultam o uso de filmes em escolas, e esta realidade se faz presente em diferentes regiões do país.

Os problemas citados acima demandam algumas ações para serem sanados: construção de salas de projeção com iluminação, sonorização, instalações, aparelhagem e segurança adequadas; disponibilização e treinamento de funcionários para a gestão do uso dessas salas 
de projeção; organização e manutenção de acervos de filmes para a utilização dos professores; divulgação, entre o alunado, das potencialidades e importância dos filmes no processo de ensino-aprendizagem etc. Quanto a este último ponto citado, vale ressaltar que muitas provas de vestibular hoje em dia tem listado filmes como fonte de consulta e conteúdo a ser analisado nas provas.

A despeito dos discursos de muitos gestores escolares, que apontam as deficiências de programas estaduais de educação no suprimento dessas demandas, vale ressaltar que as possibilidades existem, e devem ser buscadas. A respeito disto, vale citar o Programa Cine Mais Cultura, do Ministério da Cultura, que visa instrumentalizar escolas públicas na formação de cineclubes. O referido programa prevê a concessão às escolas de aparelhos de tv, de dvd, de projeção e sonorização, computador, bem como um acervo de cento e vinte filmes. Contudo, a escola deve ter uma contrapartida, com salas de projeção e de acervo que sejam seguras e tenham instalações adequadas, além de funcionários próprios. A escola deve ainda apresentar ao programa relatórios periódicos sobre o material cedido, ao longo de dois anos.

O último aspecto apontado no parágrafo anterior conduz às dificuldades burocráticas e de gestão que obstaculizam o uso de filmes nas escolas: falta de integração e interação entre os diversos atores envolvidos (gestores escolares, professores, estudantes, pais e funcionários); falta de realização de parcerias entre a escola e órgãos municipais, estaduais e federais para a viabilização dos projetos de aparelhamento audiovisual nas escolas; dificuldade de acesso a suporte técnico e de manutenção das instalações e aparelhagens etc. Frente a isto, é necessário que os diversos atores envolvidos no cotidiano escolar possam estar interessados e articulados no processo, que as escolas consigam realizar as parcerias necessárias para a implementação desses espaços de uso audiovisual, e que os usuários saibam conservar o material utilizado.

A constatação das dificuldades do uso de filmes nas escolas deve ser transcendida, e não encarada como algo negativo e restritivo, os obstáculos podem e devem ser superados. A participação de toda a comunidade escolar é essencial para superar esses obstáculos, uma vez que a escola deve ser gerida como um ambiente democrático e participativo. Diante disto, vale ressaltar a seguir algumas das possibilidades e potencialidades do uso de filmes nas escolas. 


\section{As Possibilidades e Potencialidades de Uso de Filmes nas Escolas}

As potencialidades do uso de filmes no ensino de Geografia já foram apontadas por Harvey (1992), no início deste artigo. Vale detalhar um pouco mais essa questão, pois que todo filme é ambientado em um dado local, representa uma certa realidade, e, deste modo, contém muitos aspectos a serem analisados geograficamente e discutidos em sala de aula. Uma ressalva há de ser feita, os filmes ficcionais possuem a liberdade poética e criativa do diretor, e muitas vezes não são necessariamente fidedignos à realidade representada. Cabe, frente a isto, uma análise crítica do professor antes de utilizar algum filme, bem como efetivar o seu papel de mediador nas discussões de sala de aula sobre alguma obra audiovisual.

As obras audiovisuais possuem a possibilidade de sintetizar em cerca de duas horas, tempo médio de um filme longa metragem, temas diversos e complexos. Contudo, com a síntese corre-se o risco também de simplificações, já que nenhum filme pode dar conta da totalidade e complexidade de uma determinada realidade retratada. Por conta disto, os professores devem buscar complementar a exibição de um filme com a utilização de outros recursos, tais como livros, jornais, revistas, matérias de televisão, entrevistas etc. A interdisciplinaridade e transversalidade de alguns temas retratados em certos filmes, é sem dúvida uma das grandes potencialidades do seu uso, pois que professores de diferentes áreas podem trabalhar conjuntamente certos conteúdos.

Algumas possibilidades de uso de filmes nas escolas devem ser citadas: organização e manutenção de cineclubes no ambiente escolar; sistema de empréstimo de filmes, como já é feito com os livros das bibliotecas escolares; realização de semanas temáticas sobre conteúdos específicos, com a exibição de filmes relacionados aos conteúdos; organização de grupos de estudo e discussão sobre filmes; encenação de trechos de filmes, para se debater assuntos específicos; realização de vídeos documentários na escola e seu entorno, por parte dos alunos, com a condução dos professores; realização de mesas-redondas com cineastas e videomakers; organização de fóruns de debate sobre filmes via internet etc. As possibilidades são diversas e exeqüíveis, desde que haja emprenho e envolvimento da comunidade escolar, e que sejam feitas as parcerias necessárias com outras instituições.

As potencialidades do uso de filmes como recursos didáticos também são diversas: a linguagem audiovisual permite visualizar de maneira direta processos que são visto e 
assimilados de forma mais abstrata em livros e outros recursos; o uso de filmes possibilita ter contato com representações de períodos históricos e contextos sócioespaciais diversos, que nos livros aparecem apenas através de fotos e reprodução de documentos históricos; por fim, e não menos importante, muitos dos assuntos tratados em alguns filmes são interdisciplinares e transversais, possibilitando que professores de diferentes áreas possam trabalhar em conjunto. A lista que é apresentada a seguir, por exemplo, apresenta temas que podem ser utilizados não só pela Geografia, mas também pela História, Literatura, Sociologia etc.

\section{Geografia e Filmes - Um Inventário}

Este tópico traz uma lista de vinte e cinco temas geográficos e filmes relacionados, são cinco filmes para cada tema destacado. Este inventário é destinado tanto àqueles que queiram analisar algum tema específico da Geografia e áreas afins com uso de filmes, quanto aos professores que se interessem em trabalhar com os temas em sala de aula. Muitos filmes famosos acabaram ficando de fora desta compilação, cabe a cada professor - pesquisador ampliá-la, tanto incluindo novos filmes aos temas citados, como novos temas e seus respectivos filmes, ou criando sua própria lista, e se possível, próprio acervo de filmes.

A cada tema, os filmes são listados em ordem cronológica, e dentro de um mesmo ano, em ordem alfabética dos sobrenomes dos autores. Não há uma ordem alfabética dos temas, nem uma hierarquização de grau de importância dos assuntos na lista. Os temas e conteúdos apresentados a seguir cobrem diversos assuntos trabalhados pela Geografia: política (Conflitos internos no Brasil, ditadura militar, relações de poder etc.), relações sociais (Relações de gênero, escravidão e resistência negra), migrações, espaço urbano (Favelas, violência urbana), geopolítica (Primeira e Segunda Guerras Mundiais, nazismo etc.) e tantos outros. A lista de filmes é integrada tanto por filmes clássicos da cinematografia mundial e brasileira do século passado, quanto por filmes contemporâneos, realizados na última década. 


\section{Conflitos internos no Brasil}

- A Revolução de 30 (Sylvio Back, Brasil: 1980): inspirado no documentário Pátria Redimida, de João Batista Groff, o filme consiste na colagem de mais de trinta documentários e filmes de ficção sobre a Revolução de 1930.

- Parahyba Mulher Macho (Tizuka Yamazaki, Brasil: 1983): baseado na história de Anayde Beiriz, poeta, jornalista e professora revolucionária, no período que antecedeu a morte de João Pessoa na Paraíba, e a Revolução de 1930.

- O Homem da Capa Preta (Sérgio Rezende, Brasil: 1986): cinebiografia do Deputado Tenório Cavalcante, que costumava aparecer em público utilizando uma metralhadora, e afrontando seus opositores políticos.

- O País dos Tenentes (João Batista Andrade, Brasil: 1987): no leito de morte um militar da reserva relembra os momentos importantes de sua vida, e sua participação no movimento tenentista e no Golpe de 1964.

- Guerra do Brasil (Sylvio Back, Brasil: 1987): obra que mistura documentário e ficção, além de material iconográfico e de áudio, sobre a Guerra do Paraguai, que envolveu o Brasil, Argentina, Paraguai e Uruguai.

\section{Ditadura militar}

- Pra frente, Brasil (Roberto Farias, Brasil: 1983): o filme mostra como em algumas situações, durante a ditadura militar, cidadãos comuns poderiam ser presos, tratados como revolucionários e sofrerem torturas na prisão.

- Lamarca (Sérgio Rezende, Brasil: 1994): narra a trajetória do Capitão Carlos Lamarca, que desertou do Exército por discordar das torturas, virou revolucionário, comandou treinos de guerrilha e foi morto no sertão baiano.

- O que é isso companheiro? (Bruno Barreto, Brasil: 1997): baseado no caso do sequestro do embaixador americano Charles Elbrick, pelo grupo revolucionário MR8, que posteriormente o trocou pela libertação e exílio de presos políticos.

- Cabra Cega (Toni Venturi, Brasil: 2004): a obra retrata o modus operandi de um grupo revolucionário durante o regime autoritário, e a tensão da perseguição constante a que seus membros estavam sujeitos. 
- Batismo de Sangue (Helvécio Ratton, Brasil: 2006): narra o envolvimento dos freis Beneditinos Beto, Oswaldo e Tito, com os movimentos estudantis durante a ditadura, no caso do Congresso da UNE em Ibiúna - MG.

\section{Espaço carcerário}

- Pixote, a lei do mais fraco (Hector Babenco, Brasil: 1980): mostra de maneira contundente o cotidiano de menores infratores entre as estadias na antiga FEBEM paulista, a vida nas ruas, o uso de drogas e os pequenos delitos.

- Memórias do Cárcere (Nelson Pereira dos Santos, Brasil: 1984): baseado em livro auto biográfico do escritor Graciliano Ramos, no qual é reconstruído o período em que Ramos esteve preso e foi torturado durante o Estado Novo.

- Barrela: escola de crimes (Marco Antonio Cury, Brasil: 1990): fala da convivência tensa entre seis presos confinados em uma pequena cela, esta convivência se complica com a chegada de um jovem de classe média.

- Carandiru (Hector Babenco, Brasil: 2003): baseada no livro Estação Carandiru, de Draúzio Varella, mostra o lado humano e a diversidade sociocultural entre os presos da antiga Casa de Detenção do Carandiru.

- Querô (Carlos Cortez, Brasil: 2007): um jovem órfão da baixada santista, em São Paulo, alterna seus dias entre internações sofridas na extinta FEBEM e a vida de crimes nas ruas.

\section{Relações de poder}

- O Grande Ditador (Charles Chaplin, EUA: 1940): um libelo humanista, no qual Chaplin faz uma crítica bastante perspicaz ao Regime Nazista na Alemanha da Segunda Guerra Mundial. O primeiro longa metragem falado do diretor.

- O Expresso da Meia Noite (Alan Parker, EUA: 1978): jovem é preso com haxixe em Istambul, e passa a ser transferido por diversas prisões na Turquia, sofrendo torturas e interrogatórios intermináveis.

- 1984 (Michael Radford, Inglaterra: 1984): baseado em livro homônimo do escritor George Orwell, o filme de ficção científica desenha uma sociedade futurista controlada por um ditador onipresente e onipotente. 
- Brazil, o filme (Terry Gilliam, Inglaterra: 1985): com nítida inspiração no filme citado logo acima, esta obra de ficção faz uma crítica aos sistemas totalitaristas, questionando um Estado controlador e bastante burocratizado.

- V de Vingança (James Mc Teigue, EUA: 2006): este filme dialoga com os dois anteriores, podendo ser trabalhados em bloco, comparando-os entre si. Neste último, um vingador anarquista bate de frente com um sistema autoritário.

\section{Relações de gênero}

- Amores possíveis (Sandra Werneck, Brasil: 2001): um casal e três destinos possíveis a partir de escolhas feitas na juventude, ou ficarem juntos e casados, ou viverem separados, com outros relacionamentos, ou se reencontrarem.

- A Mulher Invisível (Claudio Torres, Brasil: 2009): um jovem divide-se entre um relacionamento real, mas com os problemas cotidianos, e um relacionamento criado pela sua mente, com uma mulher invisível e, teoricamente, ideal.

- Baixio das Bestas (Cláudio Assis, Brasil: 2007): na zona da mata pernambucana, adolescentes são prostituídas pelos mais velhos, e jovens filhos de latifundiários abusam do poder político cometendo abusos sexuais.

- Divã (José Alvarenga Jr., Brasil: 2009): uma de mulher classe média, com dois filhos e um casamento em crise, se auto questiona sobre suas escolhas e incertezas com um analista, e tenta achar novas perspectivas para sua vida.

- A Concepção (José Eduardo Belmonte, Brasil: 2006): jovens de classe média alta de Brasília unem-se na vivência coletiva de um movimento sociocultural que rompe com as regras éticas e sociais predominantes na sociedade.

\section{Escravidão e resistência afro brasileira}

- Ganga Zumba (Carlos Diegues, Brasil: 1963): retrata a vida do primeiro líder do Quilombo dos Palmares, na Serra da Barriga, em Alagoas, entre os séculos XVI e XVII. Baseado em livro homônimo de João Felício dos Santos. 
- Xica da Silva (Carlos Diegues, Brasil: 1976): o filme mostra a paixão assumida publicamente entre um representante da coroa e uma ex escrava, na segunda metade do século XVIII, discute preconceito e luta de classes.

- Quilombo (Carlos Diegues, Brasil: 1984): mostra o cotidiano do Quilombo dos Palmares, por volta de 1650, a divergência entre Zumbi e Ganga Zumba, e a formação do maior exército revolucionário do período colonial.

- Quanto Vale Ou É Por Quilo? (Sérgio Bianchi, Brasil: 2005): traça um paralelo entre as antigas senzalas, e as atuais favelas e presídios, discute o papel do negro na formação da sociedade brasileira.

- Besouro (João Daniel Tikhomiroff, Brasil: 2009): o filme, ambientado no início do século XX, período pós-abolição da escravatura, mostra a história do lendário capoeirista Besouro Mangangá, sua resistência através da capoeira.

\section{Sertão brasileiro}

- Vidas Secas (Nelson Pereira dos Santos, Brasil: 1963): baseado no clássico livro homônimo de Graciliano Ramos, o filme mostra as andanças de uma família de retirantes pelo sertão brasileiro, assolados pela seca.

- Deus e o Diabo na Terra do Sol (Glauber Rocha, Brasil: 1964): o filme mostra, de maneira alegórica, a luta de classes no sertão, envolvendo o pequeno agricultor, o coronel, o líder religioso, o cangaceiro e o jagunço.

- Guerra de Canudos (Sérgio Rezende, Brasil: 1997): reconstrói o episódio o conflito ocorrido entre o Governo e um grupo religioso liderado por Antonio Conselheiro, na Vila de Canudos, então província do Pará, entre 1896 e 1897.

- Eu, Tu, Eles (Andrucha Waddington, Brasil: 2000): aborda o cotidiano de uma família atípica no sertão brasileiro, formada por uma mulher, três companheiros e vários filhos. Trata da cultura sertaneja e das relações familiares.

- Cinema Aspirinas e Urubus (Marcelo Gomes, Brasil: 2005): um alemão, representante de vendas do remédio recém criado Aspirinas, e seu ajudante nativo, rodam o sertão durante a década de 1940. 


\section{Êxodo rural no Brasil}

- Macunaíma (Joaquim Pedro de Andrade, Brasil: 1969): baseado em livro de Mário de Andrade, o filme fala de um "herói sem nenhum caráter", que nasce na selva, migra para a cidade, e vivencia todas as suas contradições sociais.

- Bye, bye, Brasil (Tizuka Yamazaki, Brasil: 1980): uma trupe de artistas mambembes roda o país com a Caravana Rolidei, fazendo espetáculos para a população mais carente, mostra as contradições regionais do Brasil.

- O homem que virou suco (João Batista de Andrade, Brasil: 1980): um poeta popular nordestino, recém chegado a São Paulo, é confundido com o assassino do dono de uma multinacional e sofre toda a opressão da metrópole.

- A marvada carne (André Klotzel, Brasil: 1985): comédia inteligente e instigante sobre retirantes nordestinos que migram para as grandes cidades em busca dos sonhos e de melhores condições de vida.

- Caminho das nuvens (Vicente Amorim, Brasil: 2003): baseado em fatos reais, uma família sai, de bicicleta do sertão pernambucano, e segue até o Rio de Janeiro, em busca de trabalho e melhor remuneração.

\section{Espaço urbano}

- Copacabana (Carla Camurati, Brasil: 2001): um fotógrafo, prestes a completar seus noventa anos de idade, relembra sua vida e todas as mudanças sócioespaciais ocorridas no célebre bairro carioca, local onde sempre viveu.

- 2 Perdidos numa noite suja (José Joffili, Brasil: 2003): baseado em peça homônima de Plínio Marcos, aborda o cotidiano de dois imigrantes brasileiros ilegais na cidade de Nova York, a vida dura no exterior e a distância de casa.

- Redentor (Cláudio Torres, Brasil: 2004): o filme mostra as contradições sócioespaciais na produção do espaço urbano, através de um escândalo imobiliário que envolve um empresário, um político e os proprietários lesados.

- Cidade Baixa (Sérgio Machado, Brasil: 2005): o cotidiano do subúrbio e do submundo da prostituição na noite da cidade de Salvador - BA, mostrado através de seus personagens, uma prostituta e dois jovens que vivem de bicos. 
- O signo da cidade (Carlos Alberto Riccelli, Brasil: 2008): um mosaico de estórias e personagens que se cruzam, neste filme que mostra de maneira lírica e contundente a vida na capital paulista.

\section{Violência urbana}

- O invasor (Beto Brant, Brasil: 2001): dois engenheiros, donos de uma empreiteira, contratam um matador para assassinar um terceiro sócio, depois do serviço feito, o pistoleiro passa a extorquir os contratantes.

- O homem do ano (José Henrique Fonseca, Brasil: 2002): um pacato trabalhador, por conta de um atrito casual acaba cometendo um assassinato, depois, contudo, segue no crime e se torna um matador de aluguel.

- Contra todos (Roberto Moreira, Brasil: 2004): o cotidiano de uma família desestruturada e comandada por um assassino profissional, na cidade de São Paulo, é mostrado de maneira ácida e contundente.

- Tropa de elite (José Padilha, Brasil: 2007): um olhar sobre o cotidiano da polícia carioca, mais precisamente sobre o BOPE, Batalhão de Operações Policiais Especiais e a luta contra o tráfico. Ver também Tropa de Elite 2.

- Última parada 174 (Bruno Barreto, Brasil: 2008): mostra a vida de Alessandro Nascimento, órfão, morador de rua, sobrevivente da Chacina da Candelária, que ficou conhecido nacionalmente pelo sequestro do Ônibus 174, em 2000.

\section{Favelas}

- Uma onda no ar (Helvécio Ratton, Brasil: 2002): baseado em uma história real, em uma favela da Grande Belo Horizonte um grupo de amigos monta a Rádio Favela, um veículo para a articulação sociocultural da comunidade.

- Cidade de Deus (Fernando Meirelles, Brasil: 2002): adaptação de livro homônimo de Paulo Lins, conta as origens da favela Cidade de Deus, no Rio de Janeiro, e o surgimento do tráfico entre as décadas de 1970 e 80. 
- Cidade dos homens (Paulo Morelli, Brasil: 2007): filme que fecha a série de televisão homônima, que durou quatro temporadas, mostra o cotidiano de dois jovens em uma favela carioca, a paternidade de um, a busca do pai por outro.

- Show de bola (Alexander Pickl, Brasil: 2008): um jovem que vive em uma favela carioca dominada pelo tráfico, divide-se entre o sonho de virar jogador de futebol, e a pressão circundante de entrar para a criminalidade.

- Era uma vez - o filme (Breno Silveira, Brasil: 2008): a obra foca no romance entre um morador de uma favela e uma jovem de classe média moradora de um bairro nobre, mostra os choques culturais entre as classes sociais no Rio.

\section{Relações de trabalho e sindicalismo}

- A greve (Sergei Mihailov Eisenstein, Rússia: 1924): clássico do cinema russo, ambientado em 1912, quando uma greve dos operários de uma fábrica é brutalmente reprimida pela polícia, a mando de um czar.

- A classe operária vai ao paraíso (Elio Petri, Itália: 1971): obra referência do cinema político italiano dos anos 1970, mostra a mudança de atitude de um operário padrão, que de trabalhador alienado passa a líder de sua categoria.

- Norma Rae (Martin Ritt, EUA: 1979): uma pequena cidade no sul dos Estados Unidos, com a maioria da população trabalhando na indústria têxtil, tem sua dinâmica alterada com a chegada de um operário politizado e questionador.

- Eles não usam black-tie (Leon Hirszman, Brasil: 1981): um movimento grevista iniciado em uma fábrica, um operário grevista preocupado com a esposa grávida resolve furar a greve, entrando em conflito com seus pais.

- Domésticas - o filme (Nando Olival e Fernando Meirelles, Brasil: 2001): mostra o cotidiano e as dificuldades do ofício de empregada doméstica, obra de ficção baseada em depoimentos reais de domésticas.

\section{Território e territorialidades}


- Amazônia em chamas (John Frankenheimer, EUA: 1994): cinebiografia de Chico Mendes, seringueiro na Amazônia acreana, que confrontou os madeireiros, foi assassinado e virou símbolo das lutas ambientais.

- Abril despedaçado (Walter Salles, Brasil: 2001): trata das disputas por terras no nordeste brasileiro no início do século passado, os conflitos entre famílias rivais que envolviam recorrentes mortes em ambos os lados envolvidos.

- Narradores de Javé (Eliane Caffé, Brasil: 2003): uma comunidade tradicional e isolada terá sua vila alagada para a construção de uma barragem, os moradores resistem em se mudarem, mas acabam sendo realocados.

- A vila (M. Night Shyamalan, EUA: 2004): uma vila tranquila e isolada, no final do século XIX, acaba sendo perturbada, quando os jovens descobrem que os mais velhos criaram esta vila se isolando do mundo exterior.

- Terra vermelha (Marco Bechis, BRA-ARG-ITA: 2008): baseado em fatos reais, mostra o conflito por terras entre os índios Guarani-Kaiowas defendendo seus territórios da invasão pelos latifundiários no Mato Grosso de Sul.

\section{Guerra Civil dos Estados Unidos}

- ... E o vento levou (Victor Fleming, EUA: 1939): clássico holywoodiano, o filme ambientado no sul dos Estados Unidos, mostra o período da Guerra Civil, ou Guerra de Secessão, entre os anos de 1861 e 1865.

- Tempo de glória (Edward Zwick, EUA: 1989): durante a Guerra Civil americana, o comando do primeiro batalhão composto exclusivamente por soldados negros é dado a um jovem branco de família influente.

- Dança com lobos (Kevin Costner, 1990): durante a Guerra Civil, um tenente do exército americano é enviado para comandar um pelotão em uma região habitada por índios Sioux, acaba se envolvendo e tomando partido dos índios.

- O Assassinato do presidente (John Gray, EUA: 1998): quatro anos após o termino da Guerra Civil, Abraham Lincoln entra para a história como o primeiro presidente americano assassinado, mostra todo o ambiente da conspiração. 
- Deuses e generais (Ronald F. Maxwell, 2003): mostra as três principais batalhas ocorridas durante a Guerra Civil nos EUA, as batalhas de Manassas, Fredericksburg e Chancellorsville, baseado no livro de Jeffrey M. Shaara's.

\section{Primeira Guerra Mundial}

- A Grande ilusão (Jean Renoir, França: 1937): durante a Primeira Guerra, em um campo de prisioneiros na fronteira franco-alemã, as dificuldades no campo de batalha leva soldados antes inimigos e se unirem em prol do bem comum.

- Ases do espaço (Jack Gold, EUA: 1976): mostra o cotidiano de um esquadrão de pilotos de combate durante a Primeira Guerra, deixando de lado o glamour que envolve esta função e mostrando o lado humano dos aviadores.

- Adeus à inocência (Delbert Mann, EUA: 1979): um grupo de jovens alemães idealistas se alistam no exército para combater durante a Primeira Guerra, e acabam descobrindo a realidade brutal e cruel da luta nas trincheiras.

- Gallipoli (Peter Weir, Inglaterra: 1981): dois jovens pilotos de corridas dos Estados Unidos alistam-se no exército, e acabam os horrores da guerra, na luta contra os turcos na trágica e lendária batalha de Gallipoli.

- Glória feita de sangue (Stanley Kubrick, EUA: 1957): em 1916, durante a Primeira Guerra, o general francês Mireau ordena um ataque suicida mal sucedido, por conta do fracasso, tenta, arbitrariamente, punir seus soldados.

\section{Segunda Guerra Mundial}

- A águia pousou (John Sturges, EUA: 1976): durante a Segunda Guerra, o primeiro-ministro inglês Winston Churchill se prepara para passar um fim de semana no interior da Inglaterra, quando sofre uma tentativa de sequestro.

- A Cruz de ferro (Sam Peckinpah, Ing.- Ale.: 1977): mostra o jogo de disputa de poder entre dois oficiais americanos combatendo contra a frente russa, num conflito em que ambos querem levar os méritos da missão empreendida. 
- Assim nascem os heróis (Robert Aldrich, EUA: 1970): em novembro de 1942, durante a Segunda Guerra Mundial, tropas britânicas e japonesas disputam o controle de um arquipélago no Pacífico Sul.

- Furyo - em nome da honra (Nagisa Oshima, Inglaterra - Japão: 1983): um grupo de prisioneiros ingleses, confinado em um acampamento japonês, sofre à mercê do Capitão Yonoi, que enlouquece na guerra, e começa a executá-los.

- Um canto de esperança (Bruce Beresford, EUA: 1997): coma invasão japonesa à Sumatra, durante a Segunda Guerra, um grupo de mulheres de diferentes nacionalidades forma um coral em um campo de concentração.

\section{Guerra do Vietnã}

- Apocalypse now (Francis Ford Coppola, EUA: 1979): um capitão do exército dos Estados Unidos tem a missão de executar um coronel americano surtado, refugiado na selva do Camboja, com um grupo de soldados fanáticos.

- Platoon (Oliver Stone, EUA: 1986): um jovem soldado americano idealista alista-se para combater na Guerra do Vietnã, no front de batalha, em contato com a brutalidade da guerra suas convicções políticas são postas a prova.

- Nascido para matar (Stanley Kubrick, EUA: 1987): o filme mostra o treinamento da Academia de Fuzileiros Navais dos EUA, onde os recrutas são adestrados como máquinas de guerra, para combater no Vietnã.

- Bom dia, Vietnã (Barry Levinson, EUA: 1987): em 1965, com Saigon, a capital vietnamita, ocupada pelo exército americano, um aeronauta passa a produzir um programa de rádio, questionando os problemas da Guerra do Vietnã.

- Pecados de guerra (Brian De Palma, EUA: 1989): durante a Guerra do Vietnã um sargento jura vingança aos vietcongues, pela morte de um soldado seu, em uma operação acaba violentando e matando uma vietcongue, e é delatado. 


\section{Guerra Fria}

- Jogos de guerra (John Badham, EUA: 1983): um jovem aficionado por computadores acessa acidentalmente o sistema de defesa norte americano, gerando um incidente que ameaça gerar uma terceira guerra mundial.

- Os eleitos - onde o futuro começa (Philip Kaufman: EUA: 1983): ao ser empossado em 1960, John F. Kennedy inicia o programa de conquista da lua pelos americanos, e um seleto grupo de militares são escolhidos para o projeto.

- Cidadão Cohn (Frank Pierson, EUA: 1992): cinebiografia de Roy Marcus Cohn, senador e braço direito de McCarthy, anti-semita e homofóbico, defendeu os ideais do Macartismo, mesmo sendo secretamente gay e judeu.

- Nixon (Oliver Stone, EUA: 1995): mostra toda a trajetória de Richard Nixon, derrotado por J.

F. Kennedy, depois duas vezes presidente dos Estados Unidos, teve sua queda política no estopim do Escândalo de Watergate.

- Adeus Lênin (Wolfgang Becker, Alemanha: 2003): em 1989, pouco antes da queda do Muro de Berlim, um jovem alemão tenta esconder de sua mãe convalescente as mudanças políticas na Berlim Oriental.

\section{Revolução Russa e socialismo}

- O Encouraçado Potemkin (Sergei Eiseinstein, Rússia: 1925): no início do século passado, na Rússia Czarista, ocorre um motim no navio russo que dá nome ao filme, este levante seria o presságio da Revolução Russa de 1917.

- Outubro (Sergei Eiseinstein, Rússia: 1928): filme que comemora o décimo aniversário da Revolução Russa, ocorrida em 1917, contou com um elenco gigantesco, formado por pessoas que participaram da luta nas ruas.

- Doutor Jivago (David Lean, EUA: 1965): o filme retrata todo o processo da Revolução Russa, sobre a ótica de um médico que participou de todo o processo, desde os momentos que antecederam, até o período posterior.

- Stalin (Ivan Passer, Hungria: 1992): cinebiografia do líder da Revolução Russa, Josef Stalin, desde o início da revolução, até a sua morte em 1953, mostra em detalhes os bastidores do poder na Rússia comunista. 
- Rasputin (Uli Edel, EUA: 1996): mostra a influência do Padre Gregório Rasputine na corte czarista russa no final do século $\mathrm{XX}$, em um período de decadência da monarquia e prenúncio da Revolução Russa.

\section{Nazismo}

- O triunfo da vontade (Leni Riefenstahl, Alemanha: 1934): filme oficial da propaganda nazista, documenta o Congresso Nacional-Socialista alemão de 1934, e exalta toda a megalomania do líder Adolph Hitler.

- Olympia (Leni Riefenstahl, Alemanha: 1938): documentário sobre os Jogos Olímpicos de Verão, na Alemanha em 1936, filme de propaganda nazista que busca exaltar o ideal de supremacia da raça ariana.

- Stalingrado (Joseph Vilsmaier, Alemanha: 1993): narra a batalha de Stalingrado, ocorrida entre 1942 e 1943, na frente oriental da Segunda Guerra Mundial, com a primeira grande derrota nazista frente à União Soviética.

- A queda, as últimas horas de Hitler (Oliver Hirschbiegel, Alemanha: 2004): os últimos dias do líder nazista, pouco antes da derrota alemã na Segunda Guerra, sob a ótica da secretaria pessoal de Adolph Hitler.

- Uma mulher contra Hitler (Marc Rothemund, Alemanha: 2005): em Munique, na Alemanha nazista de 1943, uma jovem é integrante de um grupo revolucionário de resistência, quando é presa e sentenciada à morte.

\section{Oriente Médio}

- Exodus (Otto Preminger, EUA: 1960): baseado em livro de Leon Uris, o filme conta a história de Bem Canaan, líder da resistência israelense, que consegue retirar seiscentos judeus dos campos de detenção de Chipre.

- Lawrence da Arábia (David Lean, Inglaterra: 1962): conta as andanças de um jovem tenente britânico como observador, na região da atual Arábia Saudita, sua articulação com os árabes na luta contra o domínio turco. 
- Filhos do ódio (Arthur Allan Seidelman, Israel: 1977): um jovem palestino se engaja na luta armada para vingar a morte do irmão, falecido durante um conflito armado contra israelenses em Jerusalém.

- Hanna K (Costantin Costa-Gravas, França: 1983): Hanna Kaufman, uma criança sobrevivente do Holocausto, refugiada que viveu nos Estados Unidos, advogada, se vê designada para defender um palestino acusado de terrorismo.

- A garota do tambor (George Roy Hill, EUA: 1984): um casal de terroristas palestinos mata com uma bomba um diplomata israelense, uma atriz é infiltrada pela agência de inteligência israelita no grupo terrorista para desbaratá-lo.

\section{Revolução Francesa}

- A Queda da Bastilha (Jack Conway e Robert Z. Leonard, EUA: 1935): ambientado nos conturbados anos da Revolução Francesa, fala de um triângulo amoroso entre um advogado inglês e um casal farncês.

- A Marselhesa (Jean Renoir, França: 1938): ficção em tom documental, mostra o cotidiano de Marselha, os fatos que levaram à Revolução Francesa, através das estórias de vários personagens, de cidadãos comuns ao Rei Luis XVI.

- Casanova e a Revolução (Ettore Scola, França: 1982): o encontro de um controverso escritor francês e um ativista político americano com o famoso sedutor Casanova, já idoso, durante o ápice da Revolução Francesa.

- Danton, o processo da Revolução (Andrzej Wajda, França: 1982): baseado na história do líder revolucionário francês Danton, seu confronto com o ex aliado Robespierre, no período posterior à Revolução Francesa.

- A Inglesa e o Duque (Eric Rohmer, França: 2001): trata do romance de uma aristocrata francesa que vive em Paris, com o Duque de Orleans, e mesmo sendo primo do Rei Luis XVI, um dos defensores da Revolução Francesa. 


\section{Sociedade moderna e tecnológica}

- Metrópolis (Fritz Lang, Alemana: 1926): ambientado no século XXI, uma sociedade autamente mecanizada é governada autocraticamente por um poderoso empresário. Crítica aos totalitarismos e ao capitalismo industrial.

- 2001, uma odisséia no espaço (Stanley Kubrik, Inglaterra: 1968): num futuro ainda distante, em uma nave tripulada enviada a Júpiter, toda a tripulação é morta pelo computador central. Crítica ao tecnicismo desenfreado.

- Blade runner - o caçador de andróides (Ridley Scott, EUA: 1982): no século XXI uma grande corporação desenvolve robôs replicantes, mais fortes e mais inteligentes que o homem, tais robôs se rebelam contra o ser humano.

- Denise está chamando (Hal Salwen, EUA: 1995): no mundo contemporâneo, onde as tecnologias da comunicação fazem cada mais parte do cotidiano, um grupo de amigos só se comunica pela rede de computadores e por telefones.

- Matrix (Larry e Andy Wachowski, EUA: 1999): em uma sociedade futura, os seres humanos vivem escravizados pelas máquinas, têm sua energia vital sugada, e só vivenciam uma realidade virtual criada por computadores.

\section{Cavernas}

- A guerra do fogo (Jean-Jacques Annaud, FRA-CAN: 1981): ambientado em tempos préhistóricos, o filme fala de duas tribos nômades que vivem em cavernas, seus conflitos e sua evolução em torno da descoberta do fogo.

- Sociedade dos poetas mortos (Peter Weir, CAN: 1998): alunos de uma tradicional escola dos EUA, reúnem-se em uma caverna secreta para lerem, discutirem, e questionarem os valores tradicionais da instituição.

- Náufrago (Robert Zemeckis, EUA: 2000): sobrevivente de um naufrágio passa quatro anos isolado em uma ilha deserta, até ser resgatado, neste período faz de uma caverna à beira mar a sua moradia e refúgio.

- Batman begins (Christopher Nolan, EUA: 2005): baseado no clássico quadrinho de Bob Kane e Bill Finger. Bruce Wayne é um grande empresário, que em sua caverna secreta torna-se o herói Batman, o Homem Morcego. 
- Viagem ao centro da terra (Eric Brevig, EUA: 2008): um cientista disposto a desvendar o desaparecimento do irmão, faz uma expedição a uma caverna na Islândia, na empreitada acabam chegando ao centro da Terra.

\section{Processos geológicos}

- Volcano - a fúria (Mick Jackson, EUA: 1997): em Los Angeles, um vulcão ativo desconhecido sofre uma erupção causando grande destruição na cidade, até ter seu fluxo de larvas desviado para o mar.

- O inferno de dante (Roger Donaldson, EUA: 1997): um vulcanólogo e a prefeita da cidade de Dante, nos Estados Unidos, tentam alertar a população sobre a iminência de uma erupção vulcânica, que de fato ocorre.

- Terremoto em Nova York (Terry Ingram, EUA: 1998): o cotidiano de uma família que perde um filho morto por soterramento durante um terremoto, anos depois, outro terremoto volta a assolar a cidade.

- Casa de areia (Andrucha Waddington, Brasil: 2005): uma família de portugueses imigra para viver em uma área de dunas no litoral brasileiro, e vê sua casa ser paulatinamente soterrada pelo movimento das areias das dunas.

- Tsunami (Wianfried Oelsner, Alemanha: 2005): em Rantum IV, uma plataforma de extração de gás metano no mar ao norte da Alemanha, um abalo sísmico, desencadeado por uma explosão acidental, gera uma tsunami.

\section{CONSIDERAÇÕES FINAIS}

O primeiro destaque a ser feito, é que este trabalho é uma contribuição inicial do autor a este campo de discussão relativamente novo no Brasil. A revisão bibliográfica apresentada na primeira seção serve tanto de prospecção sobre o que já foi produzido a respeito do tema, como também, de vislumbre de caminhos para estudos e pesquisas futuras. resultado da revisão apresenta onze trabalhos envolvendo o uso da linguagem audiovisual (cinema e vídeo), no ensino de Geografia, bem como cita seis trabalhos de outras áreas de conhecimento que possuem interfaces com a Geografia. 
A constatação de que existem diversas dificuldades para se utilizar filmes nas escolas e em sala de aula, tanto dificuldades infra-estruturais, como dificuldades burocráticas, é evidente. Contudo, esta constatação não deve ser tomada como algo negativo, mas sim, como ponto de partida para se sanar certas deficiências comuns à maioria das escolas da rede pública, alguns caminhos possíveis foram aqui apontados. Por outro lado, são evidenciadas também, várias possibilidades de uso do cinema nas escolas, bem como são discutidas as potencialidades do uso de filmes no ensino de Geografia.

A lista de filmes apresentada na seção anterior serve como um fichário de filmes que tratam direta ou indiretamente de temas geográficos. Esta lista por si só não constitui um recurso didático, técnicas e metodologias sobre uso da linguagem audiovisual no Ensino de Geografia deverão ser abordadas pelo autor em um artigo futuro. Além disso, é interessante que cada educador e educadora procurem criar suas próprias metodologias de uso audiovisual, adaptar e aprimorar outras metodologias às realidades específicas de cada escola, enfim, buscar uma prática reflexiva de pesquisa e experimentação.

Que este trabalho possa contribuir com a discussão em voga, e que possa também instigar professores e pesquisadores, tanto da Geografia, como de outras áreas afins, a se apropriarem da proposta de uso de filmes no ensino. Em um mundo cada vez mais influenciado pela linguagem audiovisual, em suas várias vias de veiculação, é mister que a educação também se aproprie das manifestações culturais contemporâneas, sobretudo do cinema.

\section{REFERÊNCIAS BIBLIOGRÁFICAS}

ABUD, K. M., A construção de uma Didática da História: algumas idéias sobre a utilização de filmes no ensino. In: História, São Paulo, 2003. N.22, p. 183-193.

BÉRTOLO, J., Funções educativas e científicas do filme documentário na representação de realidades espaciais. In: Inforgeo, Lisboa, 2001. N.16, p. 167-174.

BETANZO, P. B., El cine como herramienta eficaz para un aprendizage concreto, activo y reflexivo: uma experiencia em aula. Anais do Congresso Iberoamericano de Educación Metas 2012, Buenos Aires, 2010, p. 1-12. 
CAMPOS, R. R. de., Cinema, Geografia e sala de aula. In: Estudos Geográficos, Rio Claro, 2006. V. 4, N. 1, p. 15-27.

CATELLI, R. E., Coleção de Imagens: o cinema documentário na perspectiva da Escola Nova, entre os anos de 1920 e 1930. In: Educação Social, 2010. V. 31, N.111, p. 605-624.

CAVALCANTE, E. C. B., Cinema na cela de aula: o uso de filmes no Ensino de Biologia para a EJA prisional. 153p. Dissertação (Mestrado em Ensino de Ciências) - Instituto de Ciências Biológicas - UNB, Brasília, 2011.

COSTA, R. V. e CARVALHO, V. de S., A arte como ferramenta do ensino jurídico: experiência através do cinema. Anais do XIX Encontro Nacional do CONPEDI, Fortaleza, 2010, p. 51765184.

COSTA, E. D. S. da, CEREZER, C., SOKOLOVIVZ, M. da S., WILHELM, D. e TOMAZETTI, E. M., O processo audiovisual nas aulas de Filosofia. Anais do VIII Simpósio Sul-Brasileiro sobre o Ensino de Filosofia, Caxias do Sul - RS, 2010, p. 40-52.

DINIZ, F. G. e ARAÚJO, T. F. de., O uso de filmes no ensino de geografia: uma discussão sobre a representação de África. Anais do X Encontro Nacional de Prática de Ensino em Geografia, Porto Alegre, 2009, p. 21-38.

DUARTE, R. e ALEGRIA, J., Formação Estética Audiovisual: um outro olhar para o cinema a partir da educação. In: Educação \& Realidade, Porto Alegre, 2008. V. 1, N.33, p. 59-80.

DWYER, T., Sociologia, Tecnologias de Informação e Comunicação. In: Sociologia: ensino médio, Brasília, 2010. V. 15, p. 163-186.

HARVEY, D., Condição Pós-Moderna. 5a ed. São Paulo: Edições Loyola, 1992, 349p.

LEANDRO, A., Da Imagem Pedagógica à Pedagogia da Imagem: uso inadequado da imagem cinematográfica em atividades pedagógicas reforça estereótipos. In: Comunicação \& Educação, São Paulo, 2001. N. 21, p. 29-36.

PELLICER, E. G., El cine como objeto y matéria de estúdio: la experiência de Drác Magic. In: Comunicar, Barcelona, 1995. N.5, p. 69-72. 
PEREIRA, L. A. de S. e SILVEIRA, C. E. H. da., Os filmes, documentários e desenhos e o ensino da Geografia. Anais do X Encontro Nacional de Prática de Ensino em Geografia, Porto Alegre, 2009, p. 40-52.

PONTUSCHKA, N. N., A linguagem cinematográfica no ensino de Geografia. In: PONTUSCHKA, N. N. Para ensinar e aprender Geografia. São Paulo: Cortez, 2007, 383p.

RIVERO, B. M. T., O cinema como ferramenta didática no ensino de geografia. 43p. Monografia (Bacharelado em Geografia) - Instituto de Geografia - UFU, Minas Gerais, 2007.

RAMOS FILHO, E. da S., Geografia e vídeo: diálogos e vivências na educação básica e superior. In: Uni-Pluri/Versidad, Antioquia, 2009. V. 8, N.2, p. 12-27.

As lutas por terra e a atualidade da produção de vídeo documentário como instrumento de registro dos processos de produção do espaço geográfico. Anais do $X$ Encontro de Geógrafos da América Latina, São Paulo: USP, 2005, p. 112-123.

SANTOS FILHO, S. C. e NUNES, L. M. B., Elaboração de um videodocumentário na prática de ensino em geografia: o caso do vídeo sobre a Bacia do Rio Bengalas no município de Nova Friburgo. Anais do X Encontro Nacional de Prática de Ensino em Geografia, Porto Alegre, 2009, p. 30-41.

VALERO, M. P. e VERA, A. L., Medios de comunicación em clase de Geografía e Historia. In: Comunicar, Barcelona, 2009. N.11, p. 130-136.

ZANINI, M. C. e WEBER, L. I., Cinema sem pipoca, mas com debate: reflexões a cerca do uso do cinema no ensino e extensão em antropologia. In: Extensio, Florianópolis - SC, 2010. N.9, p. 87-99.

\section{Artigo recebido em 31/08/2011.}

\section{Artigo aceito em 03/02/2012.}

